\title{
Looking time: Experimenter and instruction effects
}

\author{
BRUCE T. LECKART, ${ }^{1}$ SAN DIEGO STATE COLLEGE, LARRY GEHRES, KENT STATE UNIVERSITY, \\ AND GORDON THORNTON, OHIO UNIVERSITY
}

\begin{abstract}
A 2 by 3 factorial design was used to investigate the effects of the instructions and the presence of $E$ on looking time. Two hundred thirty-nine college students viewed 30 colored stimuli of landscapes, single objects, and arrys of objects under three different sets of instructions, with $E$ either present or absent while $S$ viewed the stimuli. The results demonstrated that $E$ 's presence depressed the time spent looking at the stimuli. Evidence was also found suggesting that ambiguity in the typical instructions given $S s$ in looking-time experiments may result in artifactually long looking times. It was concluded that a more appropriate situation to investigate looking time would (1) utilize sham GSR instructions to reduce $S$ 's uncertainty concerning the experiment's purpose, and (2) arrange for $E$ 's absence while $S$ is viewing the stimuli.
\end{abstract}

A question of increasing interest to psychologists concerned with attentional behavior is "Why do we look at what we do for as long as we do?" Experiments aimed at discovering the determinants of the duration of the looking response have most frequently been called looking-time studies because the dependent variable is typically a measure of how long S looks at a visual display when he is not given a specific task to perform but asked, in one way or another, to look at the stimulus for as long as he wishes.

In a recently published bibliography Leckart and Faw (1968) list more than 100 studies conducted in the last ten years that have used looking time as the dependent variable. These studies generally indicate that the duration of the looking response, or the duration of attention, is a function of stimulus and organismic variables. One consistent finding is that the more complex and/or novel a stimulus display is, the longer it will be attended to (e.g., Berlyne, 1957, 1958; Cantor \& Cantor, 1966; Leckart, 1966). A second major finding is that subject variables are related to looking time so that Ss look longer at stimuli that are more congruent with their needs (e.g., Martin, 1964; Zamansky, 1956).

However, since the looking paradigm is a relatively new one to psychology, very little is known about the influence of the data-collection situation on the dependent variable. The purpose of this study was to determine the effects of E's presence and the instructions on looking time. It is apparent that a knowledge of the effect of these variables would provide a more solid basis for future experimentation.

\section{Subjects \\ The Ss were 240 males and females} selected from an introductory psychology course and randomly assigned to six groups. The data from one $S$ in the typical instruction-E-absent group was discarded because of apparatus failure.

\section{Apparatus}

The stimuli were 30 color slides of landscapes, single objects, and arrays of objects. The stimuli were selected from a group of 129 slides that were rated on a 7-point scale and used in previous experiments (e.g., Leckart, 1966, 1967). On the basis of these ratings the stimuli were selected from the entire complexity range.

The stimuli were projected on a white lenticular screen by a Kodak Carousel 700 projector placed $8 \mathrm{ft}$ from the screen. Ss sat in a chair placed $5 \mathrm{ft}$ from and facing the screen on which a $20 \times 30$ in. image was projected. Looking times were automatically recorded to the nearest $.2 \mathrm{sec}$ on an Esterline-Angus event recorder concealed from the Ss.

In order to determine if $S s$ in the E-absent condition were looking at the screen when the $E$ was absent, it was necessary to place a concealed second $E$ in the room to observe $S$. $A$ box $52 \times 34 \frac{1}{2} \times 26 \frac{1}{2}$ in. was constructed for concealing the second $E$. The box was painted a flat black and made to look like a file cabinet by applying labels and handles and placing "spaces" between the "drawers." The box was placed approximately $3 \mathrm{ft}$ to the left of $\mathrm{S}$. E sat inside the box at right angles to S's line of sight and viewed $S$ through a vertical "space" between the "drawers." Internal soundproofing prevented any E-produced sounds from reaching $S$. The times Ss spent attending to stimuli not presented on the screen were recorded for Ss in both the E-present and E-absent conditions.

The deceptiveness of the sham file cabinet was demonstrated by one of the authors' colleagues who, when asked what he thought of the laboratory's new file cabinet, proceeded to open a "drawer" with such conviction that he ripped the facade off.

Procedure

Design. A 2 by 3 between-Ss design was used. One variable was the presence or absence of $E$ and the other was the instructions given $\mathrm{S}$.

Instruction variable. Three different types of instructions were used. In all three conditions Ss were told they were to "look at each picture for as long as you wish" and that they were participating in a two-part experiment. In the TI (typical instructions) condition $S s$ were told the experiment was not a test of their memory, that all they had to do was look at the stimuli, and when they finished they would be given instructions for the next part. These instructions are by far the most frequently used in looking-time research.

In the GSR (galvanic skin response) condition Ss were told the experiment's purpose was to determine "the effects of external stimulation on various physiological responses." They were given a brief description of the GSR, and sham finger electrodes were attached to their left hands. They were told to look at each picture for as long as they wished, and that they would be given instructions for the next part.

In the LT (looking time) condition Ss were told that "what we are interested in is how long you look at each picture." They were also told they would by given subsequent instructions for the second part.

Immediately after Ss concluded looking at the stimuli they were all given a rating task designed to give them closure on the experiment.

Experimenter variable. Ss were ushered into the experimental room and asked to be seated facing the screen. E sat at a desk behind S. After recording some preliminary information about $S, E$ played the tape-recorded instructions. Immediately after the conclusion of the instructions a telephone on E's desk rang and was answered by $E$. The ringing of the phone was under E's control and no dial tone or earphone noises were present. $E$ said one of two things, depending on whether his presence or absence was called for by the design. For half the $\mathrm{Ss}$ in each instruction condition $E$ was present during the stimulus viewing. For the remaining Ss $E$ was absent. 
For Ss in the E-absent condition $E$ said: "Hello ... Well I have a $S$ with me right now ... Well, I've already given him the instructions so he can go ahead by himself ... OK, I'll be down in a few minutes ... Goodbye." For Ss in the E-present condition E said: "Hello ... Well, I have a $\mathrm{S}$ with me right now ... Well, all right ... I'1l talk with you later ... Goodbye." For $S s$ in the E-absent condition $S$ left immediately after the phone call asking $S$ to begin whenever he was ready. $E$ then went to an adjoining room where an impulse counter allowed him to determine when S had concluded looking at the slides.

\section{RESULTS}

For each $S$ the total time spent viewing the 30 stimuli was calculated. In order to obtain an unbiased measure of the actual time spent attending to the stimuli, the time spent looking away from the screen was subtracted from the looking-time scores for $S s$ in both the E-present and E-absent conditions. The resulting mean looking times per picture for the six conditions are presented in Fig. 1.

An analysis of these looking times indicated that the duration of attention was longer when $E$ was absent than when $E$ was present $(F=33.67, \quad d f=1 / 233$, $\mathrm{p}<.001)$. The analysis also revealed a significant instruction main effect $(F=7.31, \quad \mathrm{df}=2 / 233, \mathrm{p}<.001)$ and $\mathrm{a}$ significant Instruction by E-present interaction $(F=4.33$, df $=2 / 233, p<.05)$. Figure 1 reveals that the interaction is due to a relatively small difference between the instruction conditions when $E$ is present but a relatively large difference between the instruction conditions when $E$ is absent. The instruction main effect is mainly due to the difference between instruction conditions in the E-absent condition.

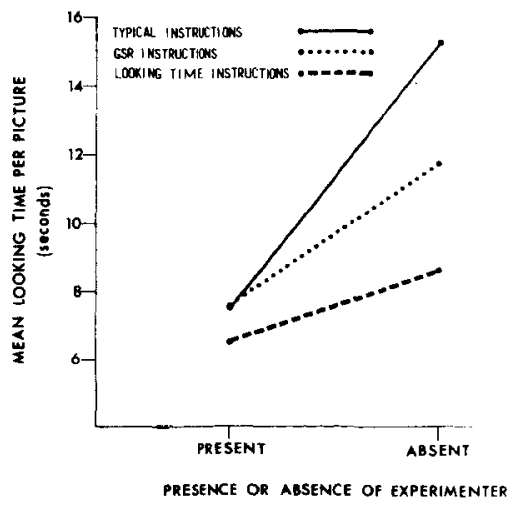

Fig. 1. Mean looking time per picture (seconds) for the six experimental conditions.

Table 1

Number of Inattentive Ss Per Group

\begin{tabular}{lrrrr} 
Experimenter & \multicolumn{4}{c}{ Instructions } \\
\cline { 2 - 5 } \begin{tabular}{l} 
Presence \\
\cline { 2 - 5 }
\end{tabular} & Typical & GSR & Looking Time & \multicolumn{1}{c}{ Totals } \\
\hline $\begin{array}{l}\text { Present } \\
\text { Absent }\end{array}$ & 3 of 40 & 3 of 40 & 0 of 40 & 6 of 120 \\
Totals & 25 of 39 & 17 of 40 & 11 of 40 & 53 of 119 \\
\hline
\end{tabular}

In order to evaluate further the effects of the instructions and the presence of $E$, the time each $S$ spent looking away from the screen in each of the six conditions was calculated. Since 180 of the 239 Ss spent no time looking away from the screen it was decided that a parametric analysis of these times would be inappropriate. Accordingly, the number of Ss that spent some time looking away from the screen was calculated for each of the six groups. These frequencies are presented in Table 1 . A chi-square test comparing the frequency of people looking away in the E-present and E-absent conditions indicated that more inattention to the screen occurred when $E$ was absent than when $E$ was present $\left(\chi^{2}=50.26\right.$, df $\left.=1, p<.001\right)$. A chi square also indicated that for the E-absent condition there was a difference between the three conditions in the frequency of looking away from the screen $\left(\chi^{2}=10.74\right.$, df $\left.=2, p<.01\right)$. The typical instructions produced the highest proportion of inattentive Ss, whereas the looking time instructions produced the lowest proportion of inattentiveness.

\section{DISCUSSION}

The results of this experiment conclusively demonstrated that the instructions and the E's presence influenced the duration of attention. For all three sets of instructions the looking times were longer when $E$ was absent than when $\mathrm{E}$ was present. It was also shown that when $E$ was present the instructions produced essentially no difference in the looking times. However, when $\mathrm{E}$ left $\mathrm{S}$ to view the stimuli by himself not only were the looking times increased for all three instruction conditions but some instruction conditions showed a greater increase than others. Specifically, E's absence had the most influence on the typical instruction condition and the least effect on the looking time condition.

The finding that Ss look longer when $E$ is absent suggests that E's presence inhibits $S$ 's looking time. One possible interpretation of this phenomenon is that when $E$ is present the $S$ attends for relatively brief periods for fear of what longer periods might reveal about himself to the psychologist conducting the experiment. It should be noted that regardless of the interpretation this finding is relevant to the large body of research that indicates that $E$ can influence the outcome of psychological research (Rosenthal, 1966). In the present case there is conclusive evidence that the mere presence of an observer dramatically affects the S's behavior. The implication of this finding for future research in this area is that $E$ should not be present while $S$ views the stimuli.

The finding that when $E$ is absent the different instructions produce large differences in looking time is also quite important. The typical instructions given $S$ are exceptionally ambiguous. He is told that all he has to do is to look at the stimuli for as long as he wishes and that the experiment is not a test of his memory. However, the results of unpublished systematic postexperimental interviewing of Ss in the senior author's laboratory indicates that at least $30 \%$ of the Ss receiving these instructions do not believe that the experiment is not a memory test. In addition, evidence has been obtained suggesting that Ss who do not believe the instructions look longer at all stimuli. This suggests that Ss receiving these instructions look longer in an attempt to remember the stimuli. Thus the relatively long looking times in the typical instruction condition in the present experiment may be produced by the suspicions of the Ss aroused by the ambiguous instructions that create, perhaps, a number of different hypotheses concerning the real purpose of the experiment. The high frequency of looking away from the screen in the typical instruction-E-absent condition further supports the view that $S s$ are formulating a hypothesis concerning the purpose of the experiment or are at least in doubt and confused about what is happening.

The relatively brief looking times in the group told that the purpose of the experiment is to measure looking times may be due to an inhibitory effect of these instructions. One possible interpretation is that these Ss look less than they "normally" would because they are afraid of what their looking times might reveal.

In conclusion, it seems reasonable that future research should use a set of instructions that, like the sham GSR instructions used in the present experiment, provide $S$ with a believable specific task that does not result in his 
formulating hypotheses that will produce either abnormally long looking times because of his uncertainty concerning what is expected of him or abnormally short looking times because of his fear of looking. It is also reasonable to conclude that future research should arrange for the $E$ 's absence while $S$ is viewing the stimuli since there is evidence that E's presence inhibits S's looking.

\section{REFERENCES}

BERLYNE, D. E. Conflict and information-theory variables as determinants of human percentual curiosity. Journal of
Experimental Psychology, 1957, 53, 399-404. BERLYNE, D. E. The influence of complexity and novelty in visual figure on orienting responses. Journal of Ex: ir nental Psychology, 1958, 55, 289-296.

CANTOR, J. H., \& CANTOR, G. N. Functions relating children's observing behavior to amount and recency of stimulus familiarization. Journal of Experimental Psychology, 1966, 72, 859-863.

LECKART, B. T. Looking time: The effects of stimulus complexity and familiarity. Perception \& Psychophysics, 1966, 1, 142-144.

LECKART, B. T., \& FAW, T. T. Looking time: A bibliography. Perceptual \& Motor Skills, 1968, 27, 91-95.
MARTIN, B. Expression and inhibition of sex motive arousal in college males. Journal of Abnomal \& Social Psychology, 1964, 68, 307-312.

ROSENTHAL, R. Experimenter effects in behavioral research. New York: Appleton-Century Crof ts, 1966.

ZAMANSKY, H. S. A technique for assessing homosexual tendencies. Journal of Personality, $1956,24,436-448$.

\section{NOTE}

1. Address: Department of Psychology, San Diego State College, San Diego, California 92115.

(Accepted for publication November 15, 1969.) 